\title{
Screening Tomato Seedlings for Multiple Disease Resistance
}

\author{
W. Alan Erb ${ }^{1}$ and Randall C. Rowe ${ }^{2}$ \\ The Ohio State University, Ohio Agricultural Research and Development Center, Wooster, \\ OH 44691 \\ Additional index words. Lycopersicon esculentum Fusarium oxysporum f. sp. radicis-lycopersici, F. oxysporum f. sp.
lycopersici, Verticillium dahliae, Meloidogyne incognita, tobacco mosaic virus
}

Abstract. Two procedures for screening tomato (Lycopersicon esculentum Mill.) seedlings for resistance to three pathogens were developed. In one scheme, seeds were sprayed with a spore suspension of Fusarium oxysporum f. sp. radicis-lycopersici Jarvis \& Shoemaker (fusarium crown and root rot). Resistant seedlings were root-dipped 2.5 weeks later in a spore suspension of Verticillium dahliae Kleb. (verticillium wilt), and 1 week following the root dip, leaves were rubbed with tobacco mosaic virus. In the other scheme, 2-week-old seedlings were dipped in a spore suspension of $F$. oxysporum Schlecht f. sp. lycopersici (Sacc.) Snyd. \& Hans. races 1 and 2 (fusarium wilt). Resistant seedlings were root-drenched 1.5 weeks later with a suspension of Meloidogyne incognita Kofoid \& White (rootknot nematode), and 1 week following, the leaves were rubbed with tobacco mosaic virus. These procedures were effective for disease screening, and their use should reduce the time required for development of two multiple disease-resistant populations. Inbreds from each population could be crossed to produce hybrids resistant to five pathogens.

Hybrid cultivars are preferred in the greenhouse tomato industry, in part because resistances to several major diseases of these tomatoes are conferred by single dominant genes that can be combined in hybrids by using inbreds possessing the dominant genes in question. Some of the greenhouse tomato diseases for which a single dominant resistance gene is available are: fusarium wilt (Fol) (Bohn and Tucker, 1940; Stall and Walter, 1965); fusarium crown and root rot (Forl) (Berry and Oakes, 1987); verticillium wilt (Verd) (Schaible et al., 1951); rootknot nematode (Meli) (Gilbert and McGuire, 1955); and tobacco mosaic virus (TMV) (Alexander, 1963).

The time required to introgress each resistance gene into commercially acceptable cultivars is a major restriction. Seedling screening techniques for resistance to all the above diseases are now available. If, however, each technique were used alone, it would take 4 to 5 years to combine all resistance genes into one line. This problem can be alleviated by screening single seedlings simultaneously for resistance to several diseases, thus significantly reducing germplasm development time.

The objective of this research was to determine the feasibility of screening seedling populations for resistance to three pathogens. In this study we modified and combined established techniques for screening for resistance to Forl (Berry and Oakes, 1987), Verd (Ben-Yephet and Pilowsky, 1979), TMV (Ciccarese and Cirulli, 1980), Fol (Wellman, 1939), and Meli, and then developed procedures to screen single seedlings for resistance to Forl, Verd, and TMV, or to Fol races 1 and 2, Meli, and TMV.

Received for publication 2 Apr. 1991. Accepted for publication 10 Feb. 1992. Salaries and research support provided by state and federal funds appropriated to the Ohio Agricultural Research and Development Center, The Ohio State Univ. Journal Article no. 71-91. We appreciate the technical support provided by N. Jean Flickinger and William R. Beery. The cost of publishing this paper was defrayed in part by the payment of page charges. Under postal regulations, this paper therefore must be hereby marked advertisement solely to indicate this fact.

${ }^{1}$ Assistant Professor, Dept. of Horticulture.

${ }^{2}$ Professor, Dept. of Plant Pathology.

\section{Materials and Methods}

Experiments were conducted during Spring and Fall 1988. In the spring, seedlings were inoculated with either Forl and Verd or with Fol 1 and 2 and Meli. In the fall, seedlings were inoculated with either Forl, Verd, and TMV or with Fol 1 and 2, Meli, and TMV. Resistant and susceptible inbreds and/or hybrids were screened in each experiment, and a segregating population was also tested in the spring experiment. Plant material was chosen according to known reactions to pathogens used in the study (Table 1). Each experiment was divided into two tests: in test 1 (Fig. 1), seedlings were inoculated with Forl, then Verd, and finally with TMV (Ohio strain \#4), and in test 2 (Fig. 2), seedlings were inoculated with Fol 1 and 2, then Meli, and finally with TMV (Ohio strain \#5). In the spring, 'Vendor', Ohio 12, ICR.12, Ohio $11 \times$ ICR.9, and Ohio $1403\left(\mathrm{~F}_{2}\right)$ were screened in test 1, and 'Vendor', Ohio 12, 214-1, Ohio $11 \times$ 214-1, and Ohio $1403\left(\mathrm{~F}_{2}\right)$ were screened in test 2. In the fall, 'Vendor', Ohio 1497, 89-1, and Ohio 12 were screened in test 1, and 'Vendor', Ohio 1497, 214-1, and ICR.17 were screened in test 2. Some of the same plant material was screened in each experiment to maintain continuity, while others were added or dropped to determine general applicability of the procedure.

Table 1. Reaction of tomato entries to the pathogens used.

\begin{tabular}{|c|c|c|c|c|c|c|}
\hline Entry & Fol 1 & Fol 2 & Forl & Verd & TMV & Meli \\
\hline Vendor (inbred) & $S^{\mathbf{z}}$ & $\mathrm{S}$ & $S$ & $S$ & $S$ & $S$ \\
\hline Ohio 12 (inbred) & $\mathrm{R}$ & $S$ & $\mathbf{S}$ & $\mathbf{S}$ & $\mathrm{S}$ & S \\
\hline $89-1$ (inbred) & $\mathrm{R}$ & $S$ & $\mathbf{R}$ & $\mathrm{R}$ & $\mathbf{R}$ & $S$ \\
\hline $214-1$ (inbred) & $\mathbf{R}$ & $\mathbf{R}$ & $S$ & $S$ & $\mathbf{R}$ & $S$ \\
\hline ICR.12 (inbred) & $\mathbf{R}$ & $S$ & $\mathbf{R}$ & $\mathbf{R}$ & $\mathrm{R}$ & $S$ \\
\hline ICR.17 (inbred) & $\mathbf{R}$ & $\mathbf{S}$ & $\mathbf{R}$ & $\mathbf{R}$ & $\mathbf{R}$ & $S$ \\
\hline Ohio $11 \times$ ICR.9 (hybrid) & $\mathrm{R}$ & $S$ & $\mathbf{R}$ & $\mathbf{R}$ & $\mathrm{R}$ & $S$ \\
\hline Ohio $11 \times 214-1$ (hybrid) & $\mathbf{R}$ & $\mathbf{R}$ & $\mathbf{R}$ & $\mathbf{R}$ & $\mathbf{R}$ & $\mathbf{R}$ \\
\hline Ohio 1497 (hybrid) & $\mathbf{R}$ & $\mathbf{R}$ & $\mathbf{R}$ & $\mathbf{R}$ & $\mathbf{R}$ & $\mathbf{R}$ \\
\hline Ohio $1403\left(\mathrm{~F}_{2}\right)$ & $\mathrm{H}$ & $\mathrm{H}$ & $\mathrm{H}$ & $\mathrm{H}$ & $\mathbf{R}$ & $\mathrm{H}$ \\
\hline
\end{tabular}

${ }^{\mathrm{z}} \mathrm{S}=$ susceptible, $\mathrm{R}=$ resistant, and $\mathrm{H}=$ segregating.

Abbreviations: Fol 1 and 2, Fusarium oxysporum f. sp. lycopersici races 1 and 2; Forl, Fusarium oxysporum f. sp. radicis-lycopersici; Mel, Meloidogyne incognita; TMV, tobacco mosaic virus; Verd, Verticillium dahliae. 


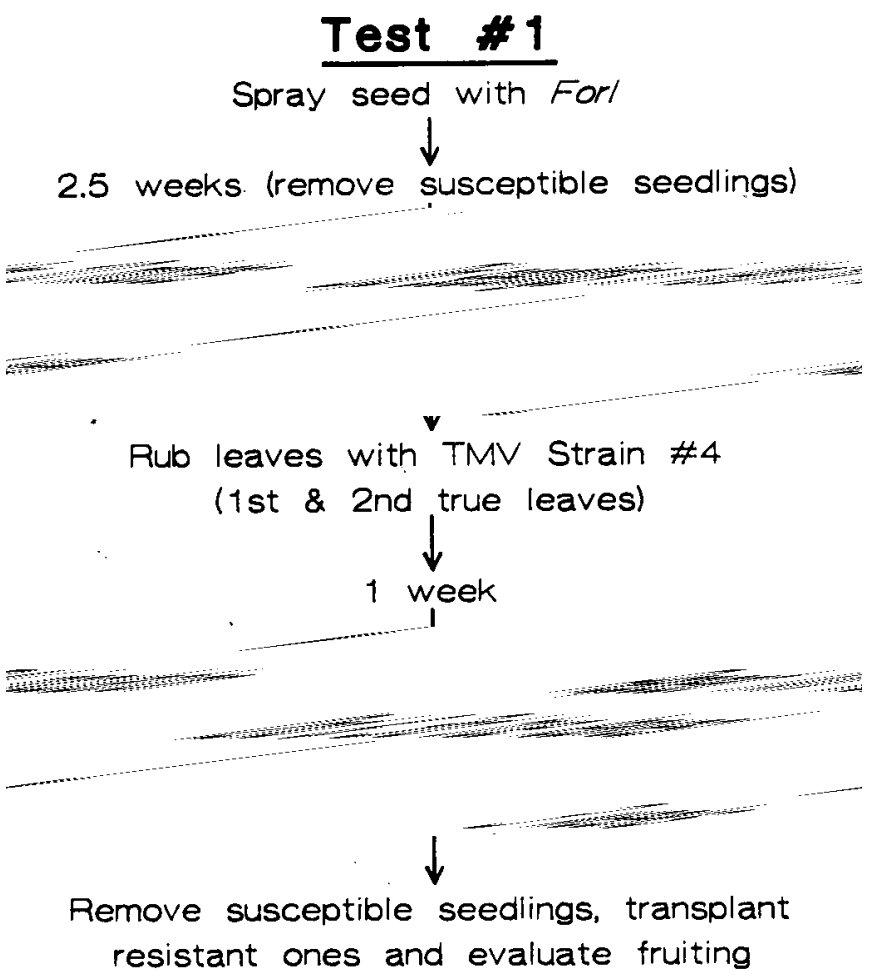

Fig. 1. Flow diagram for inoculation with Forl, Verd, and TMV, Ohio strain \#4.

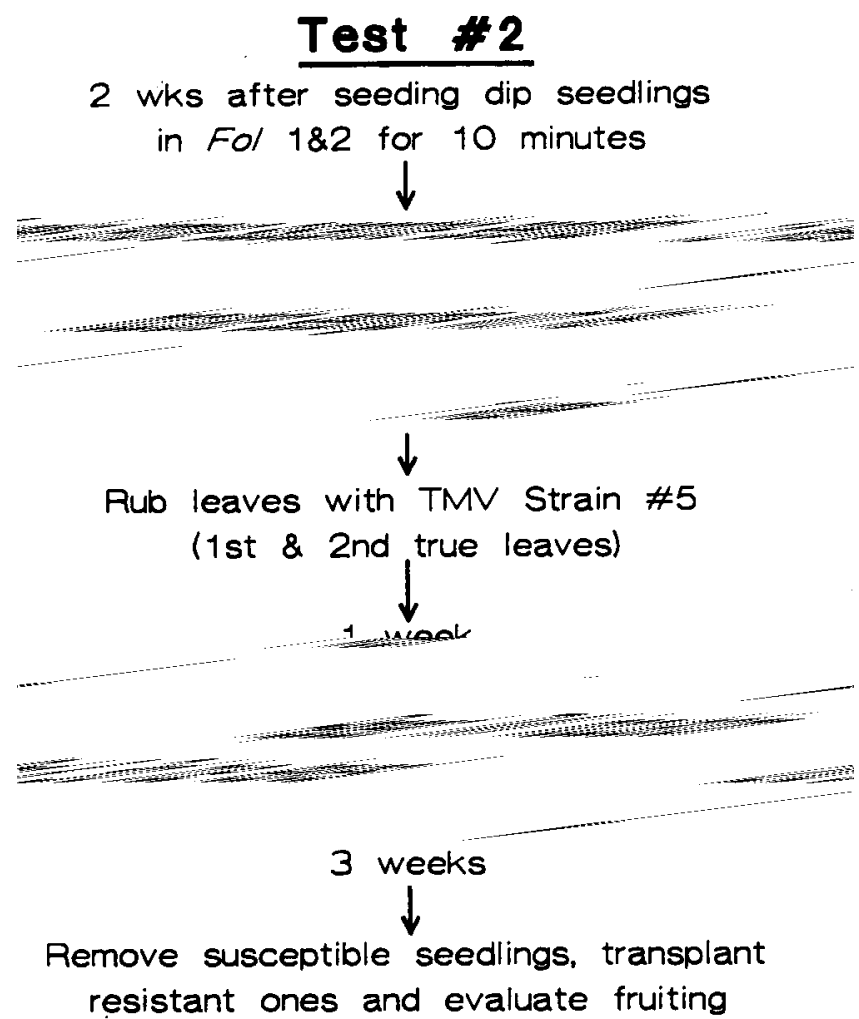

Fig. 2. Flow diagram for inoculation with Fol 1 and 2, Meli, and TMV, Ohio strain \#5.

\section{Plant culture}

In each experiment, plants were grown in $58 \times 37 \times 7-\mathrm{cm}$ wooden flats containing a sterilized 2 Cornell Peatlite Mix II : 1 Wooster silt loam soil mix ( $\mathrm{pH}$ 6-7). At least four flats were used for each pathogen. In the spring, each flat had two rows of the $F_{2}$ population (Ohio 1403) and one row of the other entries. In the fall, each flat contained one row of each entry. The number of plants per row depended on the pathogen used: Forl, 20; Verd, six to 12; Fol 1 and 2, 10 to 12; Meli, six to eight; and TMV, six. The controls for the tests were two noninoculated flats per test. Specific controls for test 1 were flats of seedlings inoculated with Verd only, TMV following Verd, or with TMV only. Specific controls for test 2 were flats of seedlings inoculated with Meli only, TMV following Meli, or with TMV only.

Each flat in test 1 was fertilized for the first time with 0.47 liters of solution containing (in mg.liter ${ }^{-1}$ ) $39 \mathrm{~N}, 85 \mathrm{P}$, and 54 $\mathrm{K}, 4$ days after being inoculated with Verd. In test 2, this same formulation was applied 4 days after inoculation with Fol 1 and 2. A second fertilization was applied 4 days after the seedlings in each test had been inoculated for the first time with TMV. Again, 0.47 liters of solution was applied, but the concentration differed [(in mg.liter $\left.{ }^{-1}\right) 87 \mathrm{~N}, 38 \mathrm{P}$, and $72 \mathrm{~K}$ ]. The greenhouse night/day sequence was $21 \mathrm{C} / 24-32 \mathrm{C}$. The plants were irrigated with $21 \mathrm{C}$ water to keep the nematodes active. The average integrated outside solar radiation was $132 \mathrm{~kW} \cdot \mathrm{m}^{-2}$ (range, 21208) and $192 \mathrm{~kW} \cdot \mathrm{m}^{-2}$ (range, 38-341) for the fall and spring experiments, respectively. In the spring, daylength was $\approx 12 \mathrm{~h}$ $50 \mathrm{~min}$ at the start of the experiment and $14 \mathrm{~h} 40 \mathrm{~min}$ at the end. In the fall, daylengths for the beginning and end of the experiments were $\approx 11 \mathrm{~h} 20 \mathrm{~min}$ and $10 \mathrm{~h} 10 \mathrm{~min}$, respectively.

To determine how this procedure would work in a breeding program, segregating populations were also screened using the procedures outlined in Figs. 1 and 2. These studies were done in large benches containing the same soil mix used previously. However, seedlings were not screened for TMV resistance because they were already homozygous for TMV resistance. In test 1 of the spring experiment, 1197 seedlings were screened for resistance to Forl and 241 for resistance to Verd. In test 2, 756 were screened for resistance to Fol 1 and 2. These seedlings were not screened for response to Meli because inoculum was depleted. Seeds were saved from 51 test 1 plants and 137 test 2 plants, and the resulting lines were rescreened in the fall experiment. In the fall, test 2 did include a Meli screen.

\section{Preparation of pathogen inoculum}

The following fungal isolates were used: Forl, isolate 471; Fol 1, isolate 415; Fol 2, isolate 465; and Verd, isolate 442. Fungal cultures were originally isolated from naturally infested tomato plants growing in commercial greenhouses. The cultures were stored at $10 \mathrm{C}$ in small bottles containing a colonized mixture of 1 silt loam soil : 1 peat : 1 perlite (by volume). Inoculum of each isolate was prepared by adding a few grams of colonized soil from the stock cultures to flasks containing $150 \mathrm{ml}$ of potato dextrose broth. Flasks then were incubated in darkness at room temperature $(\approx 25 \mathrm{C}$ ) for 4 days on a continuous rotary shaker. Before use, resultant spore suspensions were filtered through several layers of cheesecloth and the concentration of each adjusted to $5 \times 10^{6}$ conidia $/ \mathrm{ml}$ using a hemacytometer.

The Meli population used originated from a collection of naturally infected greenhouse tomato roots. It was maintained on 'Vendor' growing in pots in a greenhouse by inoculating 2week-old seedlings with galled roots every 3 months. Greenhouse and irrigation water temperatures were the same as those used in this screening study (21C). Nematodes were extracted from root cultures by use of a 24-h Baerman pie pan extraction on twenty-four 1.4-liter samples containing a mixture of soil 
and galled roots. After combining all extractions, the concentration of female nematodes was determined and then adjusted to $\approx 60 / \mathrm{ml}$.

The two Ohio strains of TMV used were maintained in frozen tobacco leaves. The TMV inoculum for each test was prepared by grinding $20 \mathrm{~g}$ of frozen TMV-infected leaves with a mortar and pestle in $20 \mathrm{ml}$ of distilled water.

\section{Inoculation procedures and disease evaluations}

In test 1 , seedlings were inoculated with Forl by spraying 5 $\mathrm{ml}$ of the spore suspension directly onto 20 dry seeds spaced equally over $38 \mathrm{~cm}$ (Berry and Oakes, 1987). Seedlings were considered susceptible if they withered and died shortly after producing cotyledons, or if the crown of the seedlings developed necrotic lesions within 2.5 weeks after inoculation. After screening for resistance to Forl, six to 12 surviving seedlings were inoculated with Verd by immersing the root systems of seedlings in $10 \mathrm{ml}$ of spore suspension for $10 \mathrm{~min}$ and then replanting the seedlings. They were considered susceptible if they were stunted $50 \%$ or more and/or had developed any external root necrosis by 5 weeks after inoculation. The TMV inoculations for both tests were accomplished by rubbing the first two true leaves of the seedlings with a pestle that had been moistened with the inoculum. One week later, seedlings were reinoculated with TMV by rubbing their second and third true leaves. Susceptibility was determined 4 weeks later by examining newly emerging foliage for characteristic light- and dark-green mosaic patterns, distortion, and stunting.

In test 2, seedlings were inoculated with Fol 1 and 2 in the same manner as the Verd inoculations. Seedlings were considered susceptible if, after 1.5 weeks, they were stunted $50 \%$ or more and/or had external root necrosis. After evaluating the seedlings for reaction to Fol 1 and 2, six to eight surviving seedlings were inoculated with Meli by pouring $2 \mathrm{ml}$ of the nematode inoculum on the roots of each plant. The presence of any root galls 5 weeks after inoculation determined susceptibility. One week after the nematode inoculation, all seedlings were inoculated with TMV, using the procedure previously described.

\section{Results}

In the spring study (test 1), the initial spray inoculation with Forl correctly identified 'Vendor' and Ohio 12 as susceptible entries (Table 2). There were, however, six escapes for 'Vendor' and 10 escapes for Ohio 12. In addition, at least $14 \%$ of the Forl-resistant entries (ICR. 12 and Ohio $11 \times$ ICR.9) exhibited symptoms indistinguishable from what was being scored as susceptible (incomplete resistant). The term "incomplete resistant" was used by Rowe (1980) to describe the incomplete penetrance of the $I$ gene, which confers Fol race 1 resistance, that he and others had observed (Alon et al., 1974; Jones and Crill, 1974; Retig et al., 1967). The high amount of incomplete resistance probably was also reflected in the failure of the $F_{2}$ population of Ohio 1403 to fit an expected 3:1 ratio.

The second inoculation in test 1 was with Verd, and the expected results for this pathogen were not affected by the previous inoculation with Forl (Table 2). There were only two escapes from infection, whether Verd was applied after Forl or alone (Table 2), and there was only one seedling evaluated as incompletely resistant. In both cases, the segregating and resistant entries fit the expected ratios. In addition, inoculating with Forl before Verd did not cause any Verd-resistant plants to exhibit incomplete resistance.
Table 2. Reaction of tomato seedlings after inoculation with Forl and then with Verd or with Verd alone. Spring 1988 experiment (test 1).

\begin{tabular}{|c|c|c|c|}
\hline Entry & Resistant & Susceptible & $\begin{array}{l}\text { Expected } \\
\text { ratio }\end{array}$ \\
\hline \multicolumn{4}{|c|}{ Reaction of plants to Forl } \\
\hline $\begin{array}{l}\text { Vendor } \\
\text { Ohio } 12\end{array}$ & $\begin{array}{r}6 \\
10\end{array}$ & $\begin{array}{r}145 \\
140\end{array}$ & $\begin{array}{l}0: 1 \\
0: 1\end{array}$ \\
\hline . & 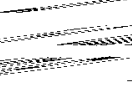 & Pass & 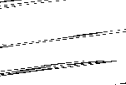 \\
\hline \multicolumn{4}{|c|}{ Mor } \\
\hline veliuvi & $u$ & 4 & $v: 1$ \\
\hline Ohio 12 & 2 & 7 & $0: 1$ \\
\hline ICR.12 & 48 & 0 & $1: 0$ \\
\hline Ohio $11 \times$ ICR.9 & 46 & 0 & $1: 0$ \\
\hline Ohio $1403\left(F_{2}\right)$ & 69 & 18 & $3: 1^{y}$ \\
\hline \multicolumn{4}{|c|}{ Reaction of plants to Verd, no Forl } \\
\hline Vendor & 1 & 35 & $0: 1$ \\
\hline Ohio 12 & 1 & 35 & $0: 1$ \\
\hline ICR.12 & 36 & 0 & $1: 0$ \\
\hline Ohio $11 \times$ ICR.9 & 35 & 1 & $1: 0$ \\
\hline Ohio $1403\left(\mathrm{~F}_{2}\right)$ & 52 & 19 & $3: 1^{x}$ \\
\hline
\end{tabular}

${ }^{\mathrm{z}} \chi^{2}=147.3$, goodness of fit, $P<0.001$.

${ }^{y} \chi^{2}=0.98$, goodness of fit, $P=0.40$.

${ }^{\mathrm{x}} \chi^{2}=0.074$, goodness of fit, $P=0.80$.

Table 3. Reaction of tomato seedlings after inoculation with Fol 1 and 2 and then with Meli or with Meli alone. Spring 1988 experiment (test 2).

\begin{tabular}{|c|c|c|c|c|}
\hline \multirow[b]{2}{*}{ Entry } & \multirow[b]{2}{*}{ Resistant } & \multirow[b]{2}{*}{ Susceptible } & \multicolumn{2}{|c|}{ Expected ratio } \\
\hline & & & Fol 1 & Fol 2 \\
\hline \multicolumn{5}{|c|}{ Reaction of plants to Fol 1 and 2} \\
\hline Vendor & 0 & 80 & $0: 1$ & $0: 1$ \\
\hline Ohio 12 & 3 & 77 & $1: 0$ & $0: 1$ \\
\hline $214-1$ & 77 & 2 & $1: 0$ & $1: 0$ \\
\hline Ohio $11 \times 214-1$ & 75 & 2 & $1: 0$ & $1: 0$ \\
\hline Ohio $1403\left(F_{2}\right)$ & 105 & 55 & $1: 0$ & $3: 1^{2}$ \\
\hline
\end{tabular}

$\begin{array}{lrrl}\text { Ohio } 12 & 0 & 3 & 0: 1 \\ 214-1 & 45 & 3 & 1: 0 \\ \text { Ohio } 11 \times 214-1 & 47 & 1 & 1: 0 \\ \text { Ohio } 1403\left(\mathrm{~F}_{2}\right) & 54 & 30 & 3: 1^{\mathrm{y}}\end{array}$

Reaction of plants to Meli, no Fol 1 and 2

\begin{tabular}{lrrl} 
Vendor & 4 & 32 & $0: 1$ \\
Ohio 12 & 0 & 36 & $0: 1$ \\
$214-1$ & 35 & 1 & $1: 0$ \\
Ohio $11 \times 214-1$ & 36 & 0 & $1: 0$ \\
Ohio $1403\left(F_{2}\right)$ & 53 & 19 & $3: 1^{\mathbf{x}}$ \\
\hline
\end{tabular}

${ }^{2} \chi^{2}=7.5$, goodness of fit, $P=0.008$.

${ }^{y} \chi^{2}=5.14$, goodness of fit, $P=0.03$.

${ }^{\times} \chi^{2}=0.074$, goodness of fit, $P=0.80$.

In test 2, after inoculating all entries with Fol 1 and 2, there were three escapes and four incompletely resistant seedlings; the expected 3:1 ratio for Ohio 1403 was rejected (Table 3). The incompletely resistant seedlings were probably the reason for the lack of fit with a 3:1 ratio. Inoculation with Meli following Fol 1 and 2 inoculations resulted in no escapes and four incompletely resistant seedlings. Because there were more sus- 
ceptible seedlings than expected, the segregating Ohio 1403 entry did not fit a 3:1 ratio (Table 3). There were no 'Vendor' seedlings to screen for reaction to Meli because they were all susceptible to Fol 1 and 2. When all entries were inoculated with Meli alone, there were four escapes and one incompleteresistant seedling. Ohio 1403 fit a 3:1 ratio for resistance to Meli (Table 3).

In the fall, results of test 1 indicated that the Forl inoculation was less effective than in the spring (Table 4). There were many escapes among the two susceptible entries and only two incompletely resistant seedlings were identified. The reaction to Verd (Table 4) was similar whether Verd followed Forl or Verd was used alone. There were a few more escapes when seedlings were inoculated with both Forl and Verd, but there were not any incompletely resistant seedlings. The TMV inoculations that followed a Verd inoculation produced no incompletely resistant seedlings, but five escapes (Table 4). When TMV was used alone (Table 4) there was no departure from the expected ratios.

In test 2, there were no escapes and 10 incompletely resistant seedlings when the entries were inoculated with Fol 1 and 2 (Table 5). Because of the lack of escapes, there were no 'Vendor' or ICR.17 seedlings to screen for reaction to Meli and TMV. The number of escapes (19) when seedlings were inoculated with Meli alone (Table 5) resulted from a lower concentration of nematodes in the inoculum. In the fall experiment,

Table 4. Reaction of tomato seedlings after inoculation with Forl, then with Verd, and then with TMV, or with Verd and then with TMV or with TMV alone. Fall 1988 experiment (test 1).

\begin{tabular}{lccc}
\hline \hline Entry & Resistant & Susceptible & Expected ratio \\
\hline & Reaction & of & plants to Forl \\
Vendor & 34 & 44 & \\
Ohio 1497 & 66 & 1 & $0: 1$ \\
$89-1$ & 77 & 1 & $1: 0$ \\
Ohio 12 & 18 & 60 & $1: 0$
\end{tabular}

Reaction of plants to Verd, following Forl

$\begin{array}{lrrl}\text { Vendor } & 1 & 32 & 0: 1 \\ \text { Ohio } 1497 & 48 & 0 & 1: 0 \\ 89-1 & 2 & 46 & 0: 1 \\ \text { Ohio } 12 & 5 & 12 & 0: 1\end{array}$

Reaction of plants to TMV, following Verd and Forl

\begin{tabular}{lccc} 
Vendor & 0 & 3 & $0: 1$ \\
Ohio 1497 & 24 & 0 & $1: 0$ \\
$89-1$ & 2 & 0 & $1: 0$ \\
Ohio 12 & 3 & 1 & $0: 1$ \\
& Reaction of plants to Verd, no Forl & \\
Vendor & 1 & 47 & $0: 1$ \\
Ohio 1497 & 48 & 0 & $1: 0$ \\
$89-1$ & 1 & 47 & $0: 1$ \\
Ohio 12 & 3 & 45 & $0: 1$ \\
& Reaction of plants to TMV, following Verd \\
Vendor & 0 & 48 & \\
Ohio 1497 & 48 & 0 & $0: 1$ \\
$89-1$ & 1 & 47 & $1: 0$ \\
Ohio 12 & 2 & 46 & $1: 0$ \\
& Reaction of plants to TMV, no Verd or Forl & \\
Vendor & 0 & 24 & $0: 1$ \\
Ohio 1497 & 24 & 0 & $0: 1$ \\
$89-1$ & 24 & 0 & $1: 0$ \\
Ohio 12 & 0 & 24 & $0: 1$ \\
\hline
\end{tabular}

J. Amer. Soc. Hort. Sci. 117(4):622-627. 1992.
Table 5. Reaction of tomato seedlings after inoculation with Fol 1 and 2, then with Meli, and then with TMV, or with Meli and then with TMV or with TMV alone. Fall 1988 experiment (test 2).

\begin{tabular}{|c|c|c|c|c|}
\hline \multirow[b]{2}{*}{ Entry } & \multirow[b]{2}{*}{ Resistant } & \multirow[b]{2}{*}{ Susceptible } & \multicolumn{2}{|c|}{ Expected ratio } \\
\hline & & & Fol 1 & $\overline{\text { Fol } 2}$ \\
\hline \multicolumn{5}{|c|}{ Reaction of plants to Fol 1 and 2} \\
\hline Vendor & 0 & 48 & $0: 1$ & $0: 1$ \\
\hline Ohio 1497 & 46 & 2 & $1: 0$ & $1: 0$ \\
\hline ICR.17 & 0 & 48 & $1: 0$ & $0: 1$ \\
\hline $214-1$ & 40 & 8 & $1: 0$ & $1: 0$ \\
\hline
\end{tabular}

Reaction of plants to Meli, following Fol 1 and 2

$\begin{array}{llll}\text { Ohio } 1497 & 38 & 0 & 1: 0 \\ 214-1 & 40 & 0 & 1: 0\end{array}$

Reaction of plants to TMV, following Meli and Fol 1 and 2

Ohio 1497

214-1

$\begin{array}{lll}30 & 0 & 1: 0 \\ 32 & 0 & 1: 0\end{array}$

Reaction of plants to Meli, no Fol 1 and 2

$\begin{array}{llrl}\text { Vendor } & 15 & 9 & 0: 1 \\ \text { Ohio } 1497 & 24 & 0 & 1: 0 \\ \text { ICR.17 } & 14 & 10 & 0: 1 \\ 214-1 & 24 & 0 & 1: 0\end{array}$

Reaction of plants to TMV, following Meli

$\begin{array}{lrrr}\text { Vendor } & 0 & 24 & 0: 1 \\ \text { Ohio } 1497 & 24 & 0 & 1: 0 \\ \text { ICR.17 } & 24 & 0 & 1: 0 \\ 214-1 & 24 & 0 & 1: 0\end{array}$

Reaction of plants to TMV, no Meli or Fol 1 and 2

\begin{tabular}{lrrr} 
Vendor & 0 & 24 & $0: 1$ \\
Ohio 1497 & 24 & 0 & $1: 0$ \\
ICR.17 & 24 & 0 & $1: 0$ \\
$214-1$ & 24 & 0 & $1: 0$ \\
\hline
\end{tabular}

Table 6. Percentage of tomato seedlings from a spring and fall experiment that either escaped inoculation with Forl, Verd, Fol 1 and 2 , Meli, or TMV or were considered expressing incomplete resistance to these pathogens.

\begin{tabular}{lcc}
\hline \hline Inoculum & Escapes & Incompletely resistant $^{\mathbf{z}}$ \\
\hline Forl & $17.0 \%$ & $10.0 \%$ \\
Verd & $2.0 \%$ & $0.8 \%$ \\
Fol 1 and 2 & $1.0 \%$ & $5.0 \%$ \\
Meli & $19.0 \%$ & $0.8 \%$ \\
\hline
\end{tabular}

${ }^{\mathrm{z}}$ Seedlings possessing the necessary gene for resistance were grouped as incompletely resistant if they exhibited symptoms indistinguishable from those scored as susceptible.

only 30 nematodes/ml could be extracted, whereas in the spring experiment, there were $\approx 60 / \mathrm{ml}$. Inoculations with TMV produced the expected ratios (Table 5).

Considering the combined results for both experiments (Table 6 ), the highest percentage of escapes occurred when seedlings were inoculated with either Forl or Meli. The other percentages are low enough that a second screening should identify any escapes. The percentage of incomplete resistance was low for all inoculations, except Forl and Fol 1 and 2.

The segregating breeding lines screened by use of the procedures outlined (Figs. 1 and 2) corroborate the results already discussed. In test 1 of the spring experiment, 241 seedlings were resistant to Forl and 956 susceptible. The Forl-resistant seed- 
lings were then screened for reaction to Verd (121 resistant and 120 susceptible). In test 2 of the spring experiment, 628 seedlings were resistant to Fol 1 and 2 and 128 susceptible.

In the fall, lines saved from the spring experiment were rescreened. The Forl screen produced 10 homozygous resistant lines, 40 heterozygous lines, and one susceptible line. The Verd screen produced two homozygous resistant lines and 12 heterozygous lines. After the completion of two screens, two lines were homozygous resistant to both Forl and Verd and eight lines were homozygous resistant to Forl and heterozygous for Verd resistance. The Fol 1 and 2 screen produced 16 homozygous resistant lines and 118 heterozygous lines. The 16 homozygous resistant lines were then screened for Meli resistance, and five appeared to be homozygous resistant, while 11 were heterozygous.

\section{Discussion}

The two procedures outlined were effective in developing multiple disease-resistant germplasm. In the two schemes, inoculation with either Forl or Fol 1 and 2 did not seem to affect the disease reaction of seedlings that were inoculated with either Verd and then TMV, or Meli and then TMV. The only previously reported interaction that might affect the results of this study is the Fol-Meli complex. Meloidogyne incognita can predispose tomato plants that are Meli susceptible and Fol resistant to the fungal parasite (Bowman and Bloom, 1966; Powell, 1971; Sidhu and Webster, 1974). Using a Fol-resistant and Meli-susceptible genotype would have clearly shown the potential for breakdown of resistance to fusarium wilt. However, this interaction is of little consequence because the goal of this screen is to identify germplasm that is homozygous resistant to both pathogens. There were problems associated with some of the singlepathogen screening techniques that resulted in escapes in the Forl and Meli screens and incomplete resistance in the Fol 1 and 2 and Forl screens.

The high percentage of escapes that occurred with Forl during the fall experiment was probably associated with the virulence of the isolate used. The isolate of Forl was not reisolated from a susceptible plant before use in the fall experiment. Continued culturing of the isolate might have reduced its virulence. In the spring, there was a low percentage of escapes $(5.3 \%)$ compared to the fall $(33 \%)$. The inoculum concentration, inoculation technique, and isolate used were all the same for both experiments. The main environmental differences between the experiments was daytime temperature and solar radiation. In the fall, daytime temperatures were only above $27 \mathrm{C}$ on one occasion. However, in the spring there were 6 days with a daytime maximum above 27C. The average integrated outside solar radiation for the fall was $132 \mathrm{~kW} \cdot \mathrm{m}^{-2}$ and the average for the spring, $192 \mathrm{~kW} \cdot \mathrm{cm}^{-2}$. Fusarium oxysporum radicis-lycopersici is considered a coolweather pathogen, preferring soil temperatures in the range of 18 to 20C (Jarvis and Shoemaker, 1978; Rowe, 1980). Because the conditions for the fall experiment were cooler, one would expect fewer escapes in the fall. We have used these screening procedures for 2 years. In Fall 1990 we compared the isolate used in this study with one we reisolated from a Forl-susceptible plant just before inoculum preparation; the isolate that was reisolated killed more seedlings and had fewer escapes.

The escapes for the Meli screen were due to a lower inoculum concentration in the fall experiment. One way to alleviate the nematode inoculum problem would be to use isozyme screening for the peroxidase enzyme that is linked to the $M i$ gene (Rick and Forbes, 1974; Medina Filho and Stevens, 1980).
Incomplete penetrance of resistance to $F o l$ is believed to be an expression of an interaction between the host genotype and inoculum concentration, seedling age, or soil temperature (Alon et al., 1974). In our study, the interactions of the host genotype with the inoculum concentration and the soil temperature are two factors that could have influenced results. At inoculum concentrations of $10^{6}$, Alon et al. (1974) reported a reduction in the penetrance of resistance genes to Fol 1 in one homozygous resistant cultivar and two heterozygous resistant hybrids as temperature decreased from 30 to $17 \mathrm{C}$. Soil temperatures were not recorded in our study, but the plants were irrigated with $21 \mathrm{C}$ water, and the greenhouse air ranged from 21 to $32 \mathrm{C}$. Incomplete resistance in seedlings genetically resistant to Forl has not been critically studied, but disease reaction probably is also influenced by inoculum concentration and soil temperature.

By using these two procedures, or screening with the isozyme rather than with live nematodes, one could develop two populations resistant to three pathogens. Once disease-resistant populations are established, recurrent selection within each population for horticultural traits can occur until superior inbreds are developed. If one starts with horticulturally acceptable germplasm, hybrids resistant to five pathogens could be produced in 2 years. These procedures could also be used to quickly introgress resistance genes into wild germplasm, thus allowing a breeder more time to concentrate on other traits while backcrossing to horticulturally acceptable germplasm. These procedures also are valuable because they represent a foundation to which other screening techniques can be added.

Critical conditions to be maintained in the screening procedures are warm irrigation water, relatively high night temperatures, and sufficient time for good symptom expression. Proper water and night temperatures are necessary to keep the nematodes active and tomato seedlings vigorous; vigorous seedlings show good symptom expression of Fol 1 and 2 within 1.5 weeks after inoculation.

\section{Literature Cited}

Alexander, L.J. 1963. Transfer of a dominant type of resistance to the four known Ohio pathogenic strains of tobacco mosaic virus (TMV) from Lycopersicon peruvianum to L. esculentum. Phytopathology 53:869. (Abstr.)

Alon, H., J. Katan, and N. Kedar. 1974. Factors affecting penetrance of resistance to Fusarium oxysporum f. sp. lycopersici in tomatoes. Phytopathology 64:455-461.

Ben-Yephet, Y. and M. Pilowsky. 1979. A method for determining susceptibility of tomatoes to Verticillium dahliae in the greenhouse. Plant Dis. Rptr. 63:66-69.

Berry, S.Z. and G.L. Oakes. 1987. Inheritance of resistance to fusarium crown and root rot in tomato. HortScience 22:110-111.

Bohn, G.W. and C.M. Tucker. 1940. Studies on fusarium wilt of the tomato. I. Immunity in Lycopersicon pimpinellifolium Mill. and its inheritance in hybrids. Missouri Agr. Expt. Sta. Res. Bul. 311:182.

Bowman, P. and J.R. Bloom. 1966. Breaking the resistance of tomato varieties to fusarium wilt by Meloidogyne incognita. Phytopathology 56:871. (Abstr.)

Ciccarese, F. and M. Cirulli. 1980. Influence of light intensity, inoculum dilution and plant age on the expression of the $T m$ resistance genes in tomato. Phytopathol. Z. 98:237-245.

Gilbert, J.C. and D.C. McGuire. 1955. One major gene for resistance to severe galling from Meloidogyne incognita. Tomato Genet. Coop. Rpt. 5:15.

Jarvis, W.R. and R.A. Shoemaker. 1978. Taxonomic status of Fusarium oxysporum causing foot and root rot of tomato. Phytopathology 68:1679-1680. 
Jones, J.P. and P. Crill. 1974. Susceptibility of "resistant" tomato cultivars to fusarium wilt. Phytopathology 64:1507-1510.

Medina Filho, H.P. and M.A. Stevens. 1980. Tomato breeding for nematode resistance: Survey of resistant varieties for horticultural characteristics and genotype of acid phosphotase. Acta Hort. 100:383393.

Powell, N.T. 1971. Interactions between nematodes and fungi in disease complexes. Annu. Rev. Phytopathol. 9:253-274.

Retig, N., N. Kedar, and J. Katan. 1967. Penetrance of gene I for fusarium resistance in the tomato. Euphytica 16:252-257.

Rick, C.M. and J. Forbes. 1974. Association of an allozyme with nematode resistance. Tomato Genet. Coop. Rpt. 24:25.

Rowe, R.C. 1980. Comparative pathogenicity and host ranges of $\mathrm{Fu}$ - sarium oxysporum isolates causing crown and root rot of greenhouse and field-grown tomatoes on North America and Japan. Phytopathology 70:1143-1148.

Schaible, L., O.S. Cannon, and V. Waddoups. 1951. Inheritance of resistance to verticillium wilt in a tomato cross. Phytopathology $41: 986-990$

Sidhu, G. and J.M. Webster. 1974. Genetics of resistance in the tomato to root-knot nematode-wilt fungus complex. J. Hered. 65:153-156.

Stall, R.E. and J.M Walter. 1965. Selection and inheritance of resistance in tomato to isolates of races 1 and 2 of the fusarium wilt organism. Phytopathology 55:1213-1215.

Wellman, F.L. 1939. A technique for studying host resistance and pathogenicity in tomato fusarium wilt. Phytopathology 29:945-956. 